\title{
Spotlight on rituximab in the treatment of antineutrophil cytoplasmic antibody-associated vasculitis: current perspectives
}

This article was published in the following Dove Press journal:

Therapeutics and Clinical Risk Management

27 November 2015

Number of times this article has been viewed

\section{Philipp Moog \\ Klaus Thuermel}

Abteilung für Nephrologie, Klinikum rechts der Isar, Technische Universität München, Munich, Germany
Correspondence: Philipp Moog Abteilung für Nephrologie, Klinikum rechts der Isar, Technische Universität München, 22 Ismaninger Strasse, Munich 81675, Germany

Tel +498941405892

Email philipp.moog@mri.tum.de
Abstract: A 54-year-old patient presented to his general practitioner because of strong muscle pain in both thighs. Inflammatory parameters (CRP $16.3 \mathrm{mg} / \mathrm{dL})$ and white blood cells $(15 \mathrm{~g} / \mathrm{L})$ were elevated. The patient reported a weight loss of $10 \mathrm{~kg}$ in 4 weeks. There was no fever or any other specific symptoms. Urine dipstick examination and computed tomography of the chest were unremarkable. Because of increasing symptoms, the patient was referred to our department. Magnetic resonance tomography showed diffuse inflammatory changes of the muscles of both thighs. Neurological examination and electrophysiology revealed axonal sensorimotor neuropathy and ground-glass opacities of both lungs had occurred. Serum creatinine increased to $229 \mu \mathrm{mol} / \mathrm{L}$ within a few days, with proteinuria of $3.3 \mathrm{~g} / \mathrm{g}$ creatinine. Kidney biopsy showed diffuse pauci-immune proliferative glomerulonephritis. Proteinase 3-specific antineutrophil cytoplasmic antibodies were markedly increased. Birmingham Vasculitis Activity Score was 35. Within 2 days, serum creatinine further increased to $495 \mu \mathrm{mol} / \mathrm{L}$. Plasma exchange, high-dose glucocorticosteroids, and hemodialysis were started. The patient received cyclophosphamide $1 \mathrm{~g}$ twice and rituximab $375 \mathrm{mg} / \mathrm{m}^{2}$ four times according to the RITUXVAS protocol. Despite ongoing therapy, hemodialysis could not be withdrawn and had to be continued over 3 weeks until diuresis normalized. Glucocorticosteroids were tapered to $20 \mathrm{mg}$ after 2 months, and serum creatinine was $133 \mu \mathrm{mol} / \mathrm{L}$. However, nephritic urinary sediment reappeared. Another dose of $1 \mathrm{~g}$ cyclophosphamide was given, and glucocorticosteroids were raised for another 4 weeks. After 6 months, the daily prednisolone dose was able to be tapered to $5 \mathrm{mg}$. Serum creatinine was $124 \mu \mathrm{mol} / \mathrm{L}$, proteinuria further decreased to $382 \mathrm{mg} / \mathrm{g}$ creatinine, and the Birmingham Vasculitis Activity Score was 0 . Maintenance therapy with rituximab $375 \mathrm{mg} / \mathrm{m}^{2}$ every 6 months was started. At the last visit after 8 months, the patient was still in remission, with only minor persistent dysesthesia of the left foot and a persistent serum creatinine of $133 \mu \mathrm{mol} / \mathrm{L}$.

Keywords: ANCA, GPA, granulomatosis with polyangiitis, MPA, microscopic polyangiitis, management

\section{Introduction}

The clinical presentation of antineutrophil cytoplasmic antibody (ANCA)-associated vasculitides (AAVs) is heterogeneous and encompasses a wide spectrum of disease manifestations, ranging from localized disease to life-threatening multiorgan vasculitis. According to the revised Chapel Hill criteria, AAVs can be further divided into different entities, namely granulomatosis with polyangiitis (GPA), microscopic polyangiitis (MPA), and eosinophilic GPA. ${ }^{1}$ A recent cluster analysis of European Vasculitis Study Group studies suggests that with respect to clinical phenotypes, it might be reasonable to distinguish even more disease subsets. ${ }^{2}$ Necrotizing small-vessel vasculitis and granuloma formation (except in MPA) are the pathological hallmarks that can lead 
to severe damage of virtually every organ system, resulting in high morbidity and mortality if untreated.

With the advent of immunosuppressive therapies, the 1-year mortality of AAVs could be reduced over time from almost $80 \%$ without any treatment to 3\%-18\% with current immunosuppressive regimens. ${ }^{3}$ Major therapeutic advances were achieved by the introduction of glucocorticoid therapy in the 1950s, cyclophosphamide in the 1970s, and most recently rituximab. ${ }^{4-7}$ This review addresses current aspects of the use of rituximab in the treatment of AAVs, and emphasizes unanswered questions for future research.

\section{Rationale for B-cell-depleting therapies - pathophysiological aspects}

The mechanisms that lead to vessel inflammation and granuloma formation are still incompletely understood. The first hints of a pathogenic role of B cells came from the detection of autoantibodies to neutrophils in patients with systemic vasculitis, with proteinase 3 (PR3) and myeloperoxidase (MPO) being the major antigens of these so-called ANCAs. ${ }^{8-10}$ Major observations that underpinned a pathogenic role for ANCAs both in vitro and in vivo will be summarized in the following paragraph. The etiology of ANCA formation and vasculitis, however, is beyond the scope of this article, and has been reviewed in detail elsewhere. ${ }^{11}$

Several in vitro findings suggest that antibody-mediated activation of neutrophils is substantially involved in endothelial damage. MPO antibodies and PR3 antibodies have been shown to activate neutrophils that were primed with tumor necrosis factor $\alpha$, lipopolysaccharide, or activated complement factor 5. ${ }^{12-14}$ ANCA-activated neutrophils produce toxic oxygen radicals by respiratory burst and form neutrophil extracellular traps that can also be found in renal vasculitic lesions. ${ }^{15}$ Furthermore, ANCA-activated neutrophils are able to destroy endothelial cells in vitro. ${ }^{16,17}$

The pathogenic effects of ANCAs have also been shown in animal models in which infusion of the antibody was sufficient to induce vasculitis. While there are convincing models for MPO-ANCAs, less evidence is available for a direct vasculitis-inducing effect of PR3-ANCA. ${ }^{18}$ Finally, the induction of systemic vasculitis in a newborn by maternalfetal antibody transfer of MPO-ANCAs supports the theory of a pathogenic role of ANCAs. ${ }^{19}$ These and other observations thus provide good evidence to target B cells, being the source of antibody production.

However, antibody production alone is not the only B-cell-mediated contribution to autoimmunity. B cells can act as antigen-presenting cells, secrete cytokines, and participate in the formation of lymphoid-like tissue in organs affected by autoimmune diseases, thereby perpetuating chronic inflammation. ${ }^{20}$

Since B-cell activation in granulomatous endonasal lesions was shown in the presence of PR3-positive cells, at least in GPA, B cells may enhance progression from a localized disease to systemic vasculitis through antigen presentation and subsequent antibody formation. ${ }^{21,22}$ Different concentrations of B-cell-specific cytokines during remission and active disease further support the importance of B cells in disease flares. ${ }^{23-25}$ Interestingly, human neutrophils have the capacity to release B-cell-activating factor and a proliferation inducing ligand (APRIL), which may lead to an amplification of the pathogenic B-cell response by ANCA-activated neutrophils. ${ }^{26}$ Taken together, the compelling evidence for a pathogenic role of $\mathrm{B}$ cells provides a strong rationale for B-cell-targeted therapies in treatment of AAVs.

\section{Pharmacology of rituximab}

Rituximab is an unconjugated chimeric monoclonal $\mathrm{IgG}_{1} \kappa$ antibody against CD20, a transmembrane protein exclusively expressed by B cells. CD20 is expressed by mature B cells, but not by stem cells, early B-cell precursors, or plasma cells. ${ }^{27}$ Before its usage in autoimmune diseases, rituximab was broadly studied and approved for B-cell lymphomas. Therefore, a large body of evidence about pharmacodynamics and pharmacokinetics comes from hematological studies of the antibody, and the mechanisms of action are summarized herein.

\section{Pharmacodynamics}

Rituximab effectively depletes B cells, mostly by three different mechanisms: complement-dependent cytotoxicity, antibody-dependent cell-mediated cytotoxicity, and signaling-induced cell death. ${ }^{28}$ Although these mechanisms are well characterized in in vitro and animal models, it is less clear to what extent they contribute to B-cell depletion in humans. However, it seems evident that signaling-induced cell death by specific homotypic binding to CD20 is the least important of these mechanisms in vivo. ${ }^{28}$

Most of the effective B-cell-depleting properties result from either nonspecific binding of the antibody Fc region to Fc $\gamma$ receptors on immune effector cells (natural killer cells, macrophages, neutrophils) in the case of antibodydependent cell-mediated cytotoxicity or from binding to $\mathrm{C} 1 \mathrm{q}$ and subsequent activation of the classical complement cascade in the case of complement-dependent cytotoxicity. 
In addition, like other IgG molecules, rituximab can bind to epithelial cells and endothelial cells of various organs through binding to FcRn (Brambell receptor). This receptor is abundant in the human placenta, and facilitates transport of maternal IgG to the fetus..$^{29}$ However, the receptor is also persistently expressed by different organs in adults, and has an important influence on the half-life of IgG and accordingly therapeutic antibodies by protecting them from degradation. ${ }^{30}$ After pinocytosis of $\mathrm{IgG}$ molecules, FcRn binds to $\mathrm{IgG}$ in the acidic environment of the endosome ( $\mathrm{pH}$ 6-6.5), and thereby initially preserves IgG from proteolysis. Dependent on the cell type, IgG molecules can then be transported to the opposite cell surface (transcytosis), back to the same cell surface, or to the lysosome for subsequent degradation. The degree of the IgG-conserving properties of FcRn is shown by experiments in FcRn-knockout mice, in which the elimination rate of IgG is increased ten- to 15 -fold. ${ }^{31,32}$ While antibody recycling prolongs the half-life of rituximab, the mechanism of transcytosis seems to play an important role in antibody delivery to different target tissues. With regard to AAVs, this may be of particular importance in the case of granulomatous manifestations.

\section{Pharmacokinetics}

In general, similarly to pharmacokinetics of small molecules, rituximab underlies different processes that influence its therapeutic effectiveness. These are absorption, distribution, degradation, and secretion. Rituximab binds with high affinity to B cells in blood vessels, lymph nodes, and bone marrow. Furthermore, it is able to leave blood vessels and bind to B cells of adjacent tissues, either by paracellular convective transport or by transcytosis. ${ }^{33}$ Rituximab is effectively distributed throughout extravascular spaces, except the central nervous system. ${ }^{34}$ Pharmacokinetic studies have shown that a steady state can be achieved after five infusions of a weekly regimen of $375 \mathrm{mg} / \mathrm{m}^{2}$. Until this point in time, the serum trough levels of the antibody still rise between each infusion. ${ }^{35}$ When it comes to elimination, different mechanisms are involved, predominantly target-mediated elimination, proteolysis by phagocytizing cells, unspecific endocytosis, and lysosomal degradation via pinocytosis. Renal excretion by glomerular filtration does not play a role for the elimination of intact rituximab, due to its high molecular weight (143.4 kDa).

Of the aforementioned mechanisms, target-mediated elimination seems to play a minor role compared to the others, as CD20 is internalized relatively slowly by B cells. ${ }^{34}$ However, as rituximab is a type I IgG antibody, its internalization may be accelerated by Fc $\gamma$ RIIB (CD32B), and thus can render B cells less accessible for FcyRIIIA of phagocytes. ${ }^{36,37}$ It has recently been shown that patients with systemic lupus erythematosus and rheumatoid arthritis have a highly variable rate of rituximab internalization, and the internalization rate was inversely correlated with B-cell depletion. ${ }^{38}$ Additionally, in cases of large amounts of available antigen (eg, in lymphomas), the absorption of rituximab by the tumor mass itself may contribute to the clearance of the circulating antibody. Given the presumably lower number of pathogenic B cells in autoimmune diseases, this is probably less important in these conditions.

Phagocytosis of opsonized B cells by the reticuloendothelial system appears to be the most important mechanism of rituximab elimination. ${ }^{39}$ The CD20-rituximab immunocomplex can also be "shaved" from the cell membrane, a mechanism called trogocytosis. ${ }^{39}$ The surviving B cells thereby express less CD20 on their surface and thus are less able to be attacked by rituximab, a mechanism that may explain why some patients respond to a lesser extent than others to rituximab treatment.

Taken together, distribution and elimination of rituximab determine the half-life of the antibody and affect therapeutically important parameters like area under the curve (AUC) and trough concentrations. According to pharmacokinetic studies, the median elimination half-life of rituximab is about 3 weeks and its median clearance about $18 \mathrm{~mL} / \mathrm{h} .{ }^{35}$ However, it is worth mentioning that marked interindividual differences can be observed in regard to pharmacokinetics. This is the case in particular for sex differences. Trough concentrations of rituximab and AUCs are higher in females than in males, and females thus had better clinical responses in several studies of lymphoma treatment. ${ }^{40-42}$ As already mentioned, internalization of CD20-bound rituximab from the cell surface seems to underlie interindividual differences. ${ }^{38}$ Finally, genetic polymorphisms of FcyRIIIA may influence response to treatment by affecting the efficacy of B-cell phagocytosis; at least, this has been observed in patients with follicular lymphoma. ${ }^{43}$ Whether these interindividual differences to treatment efficacy can be transferred to vasculitis patients, however, is currently unclear and deserves further evaluation.

\section{Implications for therapeutic drug dosing}

At least for hematological malignancies, it has been shown that drug concentrations correlate with clinical response and therefore deserve attention. Patients with lower trough concentrations or AUC values had poorer responses in 
some studies. ${ }^{41,44,45}$ Fewer data are available that correlate pharmacokinetic data of rituximab with clinical efficacy in autoimmune diseases. ${ }^{38,46,47}$ Dosing regimens for remission induction of AAVs have been mainly adopted by lymphoma protocols $\left(4 \times 375 \mathrm{mg} / \mathrm{m}^{2}\right)$ and RA protocols $(2 \times 1,000 \mathrm{mg})$, although it is not clear whether lower doses would be sufficient for particular patients. Notably, the kinetics of rituximab and B-cell depletion have been studied in pretransplant dialysis patients for reduction of human leukocyte-antigen antibodies. Single doses of 50,150 , or $375 \mathrm{mg} / \mathrm{m}^{2}$ were administered, and similar B-cell depletion with slow B-cell recovery was observed in all three groups, suggesting that lower doses might be required in nonmalignant conditions, due to a lower B-cell burden. ${ }^{48}$ Accordingly, lower doses of rituximab have been successfully used in different autoimmune diseases. ${ }^{49-53}$ However, we and others have studied low-dose rituximab in small cohorts of AAV patients with conflicting results. ${ }^{54,55}$

\section{Rituximab for GPA and MPA}

Without any doubt, by the accumulated evidence since the first published case in $2001,{ }^{56}$ rituximab has become a valuable alternative treatment for AAVs. Two randomized controlled trials have independently shown its noninferiority to cyclophosphamide in severe newly diagnosed or relapsing MPA or GPA, and rituximab has been approved for these indications by several international regulatory agencies. ${ }^{6,7}$ Moreover, rituximab has been studied in localized and refractory disease, even though most of these studies had an uncontrolled and/or retrospective design. ${ }^{57-63}$ There is also growing evidence of efficacy in eosinophilic GPA patients, but this topic is beyond the scope of this review. ${ }^{64,65}$

\section{Remission induction}

Cyclophosphamide-based regimens are very effective in inducing remission in patients with AAVs. However, as cyclophosphamide treatment may be associated with major side effects, in particular, impaired fertility, infections, and malignancy, less toxic alternatives would be desirable. The rationale for B-cell-depleting therapy was discussed earlier in this article, and for the first time rituximab was successfully applied in a patient with considerable side effects after preceding cyclophosphamide courses. ${ }^{56}$ Subsequent uncontrolled series of refractory localized or systemic manifestations showed very promising results in nearly all patients treated with rituximab. ${ }^{66,67}$ Ultimately, rituximab efficacy was shown in direct comparison to cyclophosphamide (followed by azathioprine) in two pivotal prospective randomized controlled multicenter trials: RAVE and RITUXVAS. ${ }^{6,7}$ Although the key conclusion of both studies is roughly the same, there are important differences in study designs and patients' characteristics that have already been extensively discussed and reviewed elsewhere. ${ }^{68-70}$ For instance, patients in RITUXVAS were older and had worse kidney function than RAVE patients. Primary outcome was steroid-free remission in RAVE, whereas patients in RITUXVAS were allowed to remain on concomitant low-dose steroid therapy to fulfill the primary outcome criterion of sustained remission. The strict primary outcome of complete steroid-free remission most probably accounts for the fact that fewer patients (64\%) achieved complete remission after 6 months than in cyclophosphamide studies with comparably ill patients. However, even after 18 months, remission rates did not differ significantly between the rituximab group that had no adjunctive immunosuppressive treatment and the cyclophosphamide group that had ongoing azathioprine treatment (39\% vs 33\%, respectively). ${ }^{71}$ PR3-ANCA-positive patients were at higher risk for relapse than MPO-ANCA-positive patients, and importantly relapsing patients responded better to rituximab than to cyclophosphamide. ${ }^{7,71}$ Unexpectedly, the rates of infectious complications were similar in both treatment arms during follow-up..$^{6,71}$ This can partly be explained by acquired immunodeficiency due to long-term immunosuppression with prior cyclophosphamide exposure in many patients and by concomitant high-dose corticosteroid therapy. Whether rituximab holds safety advantages over cyclophosphamide in the long-term has to be clarified by prolonged observations.

The major limitations of the randomized trials were the relatively short follow-up periods and the exclusion of certain disease subsets, in particular localized disease, ANCA-negative disease, life-threatening alveolar hemorrhage, and refractory disease. Therefore, the results of RAVE and RITUXVAS cannot readily be extrapolated to all disease subsets. Since the publication of these pivotal trials, there is growing evidence that MPA and GPA are more heterogeneous diseases than supposed before. In addition, new evidence on rituximab efficacy for different disease subsets has arisen in recent years, and will be discussed subsequently.

In regard to the clinical phenotype, recent findings suggest that it might be reasonable to distinguish more than two disease subsets (GPA and MPA). A cluster analysis of European Vasculitis Study Group studies revealed five different phenotype clusters that differed in terms of clinically relevant prognostic parameters, such as survival rates and relapse rates. ${ }^{2}$ 
Moreover, GPA and MPA seem to have distinct genetic determinants that may affect clinical phenotypes, and thereby in the future may influence treatment decisions. ${ }^{72}$ As already mentioned, PR3-positive patients and patients with GPA had higher relapse rates than patients with MPO antibodies or MPA. ${ }^{71}$ In the randomized controlled trials, there were no obvious differences in clinical outcomes between disease subsets, although it has to be stated that both studies were not powered to investigate this. A recent post hoc analysis of the RAVE trial added further insights. It revealed similar efficacy of cyclophosphamide and rituximab in patients with renal involvement, irrespective of diagnosis or antibody specificity. ${ }^{73}$ Biomarker data suggest that there may be differences in regard to antibody specificity. Patients with PR3-ANCAs at baseline had a higher probability for being ANCA-negative after rituximab treatment than patients with MPO-ANCAs. ${ }^{7}$ However, whether persistence of ANCAs is of clinical importance is still a matter of debate, as there are conflicting data about relapse risks in association with ANCA titers. $^{74-77}$ Another post hoc analysis of RAVE investigated treatment responses by ANCA subtype. In PR3-ANCA patients, rituximab was superior to cyclophosphamide and noninferior in MPO-ANCA patients.

Patients with refractory disease represent a special issue, in particular if they present with predominantly granulomatous manifestations. In a German cohort study, cyclophosphamide-refractory GPA patients with localized $(n=9)$ or systemic $(n=50)$ disease were treated with rituximab. Remission was achieved in $9.3 \%$, response to treatment in $61.3 \%$, and $26.7 \%$ of patients remained refractory. ${ }^{60}$ Whereas vasculitic manifestations responded well to rituximab treatment, significantly lower response rates were seen in granulomatous manifestations, in particular in cases with orbital masses. This has also been shown in a French retrospective multicenter study. None of five patients with orbital granulomas responded to rituximab. ${ }^{63}$ In contrast, pulmonary granuloma seem to respond better. Charles et $\mathrm{al}^{63}$ reported complete remission in 12 of $16(77 \%)$ patients with pulmonary nodules, and a case series of five patients with pulmonary nodules reported sustained efficacy in all patients over a follow-up of 18 months. ${ }^{78}$ The reasons for these differences are not fully understood, but distinct tissue-specific reactions to granulomatous inflammations have been postulated that make granuloma-associated B cells more or less prone to immunosuppressive agents. ${ }^{60}$

There are only limited data on rituximab efficacy in ANCA-negative disease. In total, 33 published cases were identified. Some reports suggested that ANCA-negative patients may respond well to rituximab, but most of the reports comprised ANCA-positive and a minority of ANCA-negative patients, and isolated investigation of ANCA-negative patients would be certainly more informative..$^{54,61,63,79-82}$

Moreover, it is currently unclear whether patients with life-threatening disease, in particular alveolar hemorrhage with need for mechanical ventilation, respond sufficiently to rituximab. These patients were excluded from randomized controlled trials. A recent retrospective analysis of 31 patients from the Mayo Clinic, however, suggests that rituximab might even be superior to cyclophosphamide in this situation. ${ }^{83}$

Whether rituximab should be preferred over cyclophosphamide as a first-line agent in severe AAVs is still a matter of debate. ${ }^{69,70}$ The available evidence provides some guidance for the choice of treatment in the individual patient. It may be reasonable to treat relapsing patients and PR3-positive GPA patients with rituximab rather than with cyclophosphamide, as rituximab seems to be superior in these situations. In young patients with fertility concerns, rituximab should be favored as well. However, the long-term efficacy of rituximab remains to be further characterized, and the established longstanding experience with cyclophosphamide as an effective remission-inducing drug justifies its further use, in particular in areas of uncertainty, such as life-threatening disease, ANCA-negative disease, or severe granulomatous disease.

\section{Maintenance therapy}

Despite induction with oral cyclophosphamide in the cyclophosphamide in systemic vasculitis (CYCLOPS) trial, ${ }^{84}$ patients had a relapse rate of $20.8 \%$ after a median of 4.3 years. The relapse rate in patients treated with intravenous cyclophosphamide was even higher $-39.5 \%{ }^{85}$ Overall, in AAVs, relapses occur at a rate of $50 \%$ after 5 years. ${ }^{86}$ In the rituximab for ANCA-associated vasculitis (RAVE) trial, ${ }^{7}$ complete remission, defined as a Birmingham Vasculitis Activity Score/Wegener's granulomatosis of 0 and the successful taper of prednisone at 6 months, was achieved in $64 \%$ of patients. However, after 12 and 18 months, complete remission faded to $48 \%$ and $39 \%$, respectively. ${ }^{71}$ After induction with intravenous cyclophosphamide, complete remission was reached in 54\% initially, and decreased to $39 \%$ at 12 months and $33 \%$ at 18 months. In the Rituximab versus Cyclophosphamide in ANCA Associated Renal Vasculitis (RITUXVAS) trial, ${ }^{6}$ relapses occurred in $21 \%$ of rituximabtreated patients and in $18 \%$ of cyclophosphamide-treated patients at 24 months. ${ }^{87}$ These data clearly highlight the need for maintenance therapy after remission induction with cyclophosphamide as well as with rituximab. 
Azathioprine has become the mainstay of maintenance therapy in AAVs, mainly on the basis of the cyclophosphamide versus azathioprine for remission in generalised vasculitis (CYCAZAREM) trial, ${ }^{88}$ which found azathioprine to be as effective as oral cyclophosphamide after induction with oral cyclophosphamide. The first randomized prospective study addressing whether rituximab might be effective in the maintenance therapy of AAVs was the Maintenance of Remission using Rituximab in Systemic ANCA-associated Vasculitis 1 (MAINRITSAN) trial (NCT00748644). ${ }^{89}$ This trial included patients with newly diagnosed AAVs. After remission induction with intravenous cyclophosphamide and glucocorticosteroids, patients with GPA (76\%), MPA (20\%), and renal-limited AAVs (4\%) received daily azathioprine or rituximab $500 \mathrm{mg}$ on days 0 and 14 and at months 6,12 , and 18 after study entry. The primary end point was major relapse, defined as reappearance or worsening of the disease with a Birmingham Vasculitis Activity Score $>0$ and involvement of a major organ, a life-threatening manifestation, or both. A major relapse occurred in $5 \%$ of patients treated with rituximab compared to $29 \%$ of patients treated with azathioprine. However, the mean prednisone dose at study entry was $17.6 \pm 7.3 \mathrm{mg}$ per day, a dose that precludes remission by definition of the European League Against Rheumatism, which proposes a dose of $\leq 7.5 \mathrm{mg}$ per day..$^{90}$ Furthermore, azathioprine was tapered after 12 months to $1.5 \mathrm{mg} / \mathrm{kg}$ /day and after 18 months to $1 \mathrm{mg} / \mathrm{kg} /$ day before it was stopped after 22 months, and thus probably was underdosed. Nevertheless, this study proved for the first time that rituximab is effective in the maintenance therapy of AAVs.

The efficacy and safety of rituximab in the maintenance therapy of AAV after remission induction with rituximab is being addressed in an international, open label, randomised controlled trial comparing rituximab with azathioprine as maintenance therapy in relapsing ANCA-associated vasculitis (RITAZAREM; NCT01697267), which is focusing on patients with relapsing AAVs. After induction therapy according to the RAVE trial, patients are randomized to $1,000 \mathrm{mg}$ rituximab at months $4,8,12,16$, and 20 or to azathioprine $2 \mathrm{mg} / \mathrm{kg} /$ day. For randomization, prednisolone at a dose of $\leq 10 \mathrm{mg} /$ day is required. After tapering, prednisolone is completely withdrawn at month 20 . The primary objective is to demonstrate the superiority of rituximab against azathioprine in the prevention of disease flares. The estimated primary completion is December 2016.

The evidence for the duration of maintenance therapy with rituximab of about 2 years and the rationale for the RITAZAREM trial come from retrospective data of a cohort of AAV patients. In this observation, patients who received $1,000 \mathrm{mg}$ rituximab every 6 months for 2 years had a prolonged relapse-free survival at a median of 44 months of follow-up. ${ }^{91}$ However, up to now, it is not clear whether rituximab should be completely withdrawn after 2 years, be replaced by an alternative agent, eg, azathioprine or methotrexate, or be continued. A retrospective observation described long-term maintenance therapy in AAVs with rituximab $1,000 \mathrm{mg}$ every 3-4 months for more than 2 years, with a low relapse rate and a reasonable safety profile. ${ }^{92}$ However, $57 \%$ of patients had MPO-ANCAs, and thus the cohort may not be representative of GPA patients with a high risk of relapse.

There have been different attempts to reduce further the relapse rate in the maintenance therapy of AAVs. A recent meta-analysis suggested that low-dose glucocorticosteroids reduce the frequency of relapses. ${ }^{93,94}$ Furthermore, a preliminary retrospective single-centre experience suggested that concomitant conventional maintenance agents could reduce the incidence of relapses. ${ }^{95}$ However, to evaluate these hypotheses, directly comparative studies over several years would be necessary.

With regard to potential side effects of long-term rituximab, an on-demand strategy based on prognostic biomarkers has been proposed to reduce the cumulative rituximab dose. All patients in the RITUXIVAS trial and $88 \%$ in the RAVE trial had B-cell reconstitution at the time of relapse. However, the time range between B-cell reconstitution and relapse was 1-286 days in the RAVE trial. The timing of repeated rituximab applications with fixed time intervals therefore might lead to an overdose. Although increases in the ANCA titer did not predict relapses in the RAVE trial, in a retrospective observation all relapses occurred after B-cell reconstitution and an increase in ANCA levels. ${ }^{59} \mathrm{In}$ the Maintenance of Remission using Rituximab in Systemic ANCA-associated Vasculitis 2 (MAINRITSAN 2) trial (NCT01731561), rituximab $500 \mathrm{mg}$ every 6 months will be compared to triggered rituximab applications based on B-cell reconstitution and ANCA increase.

\section{Safety}

In the RAVE and RITUXIVAS trials, rituximab unexpectedly equaled the number and patterns of adverse events in cyclophosphamide-treated patients with only slight differences, highlighting the need for meticulous monitoring of patients receiving rituximab. ${ }^{6,7}$ With special regard to bacterial infections, these aspects have been confirmed from cohort observations. ${ }^{63}$ However, there is substantial additional influence from disease severity, previous medication, and the pattern of organ involvement, as demonstrated from the data of patients with end-stage renal disease from the RITUXIVAS 
trial. ${ }^{6}$ However, data from randomized and nonrandomized observations suggest that overall, rituximab seems to have a reasonable safety profile in consideration of the severity of the disease and compared to alternative therapeutic options. ${ }^{89,92}$

With regard to infections, there are concerns about hypogammaglobulinemia, which has been reported to occur in up to a quarter of GPA patients receiving rituximab maintenance. ${ }^{96}$ However, a substantial part of hypogammaglobulinemia is caused by previous cyclophosphamides or other immunosuppressants, and long-term rituximab treatment is possible without severe hypogammaglobulinemia in most patients. ${ }^{89,92,97,98}$ In the case of hypogammaglobulinemia and recurrent or persistent infections, IgG replacement has been shown to be useful. ${ }^{99}$ IgG levels should therefore be monitored under rituximab therapy.

Because of potential hepatitis $B$ reactivation, hepatitis monitoring should be performed before rituximab is started, and in the case of latent hepatitis B infection lamivudine is recommended. Another potential complication of rituximab therapy is JC-polyomavirus reactivation leading to progressive multifocal leukoencephalopathy, which has been reported in single patients with different autoimmune diseases under therapy with rituximab and other biologic therapies. Up to now, there has been no consistent evidence for malignancies in AAV patients treated with rituximab. Late-onset neutropenia occurs in a minority of patients, precedes B-cell recovery. It seems not to be associated with an increased risk for infections. ${ }^{96}$

\section{Conclusion and future perspectives}

Rituximab is a potent agent to induce and maintain remission in patients with AAVs. Although its safety profile in the long term is expected to be better than that of cyclophosphamide, this hypothesis has to be answered by randomized controlled trials and by registry data. Moreover, the optimal initial dosing regimen, the timing of subsequent infusions, and the duration of maintenance therapy remain to be elucidated. Finally, the need for and the amount of concomitant immunosuppressive therapy, in particular corticosteroid dosing, has to be investigated more precisely.

\section{Disclosure}

The authors report no conflicts of interest in this work.

\section{References}

1. Jennette JC, Falk RJ, Bacon PA, et al. 2012 Revised International Chapel Hill Consensus Conference nomenclature of vasculitides. Arthritis Rheumatol. 2013;65(1):1-11.

2. Mahr A, Katsahian S, Varet H, et al. Revisiting the classification of clinical phenotypes of anti-neutrophil cytoplasmic antibody-associated vasculitis: a cluster analysis. Ann Rheum Dis. 2013;72(6):1003-1010.
3. Mukhtyar C, Flossmann O, Hellmich B, et al. Outcomes from studies of antineutrophil cytoplasm antibody associated vasculitis: a systematic review by the European League Against Rheumatism systemic vasculitis task force. Ann Rheum Dis. 2008;67(7):1004-1010.

4. Beidleman B. Wegener's granulomatosis: prolonged therapy with large doses of steroids. JAMA. 1963;186(9):827-830.

5. Fauci AS, Wolff SM, Johnson JS. Effect of cyclophosphamide upon the immune response in Wegener's granulomatosis. N Engl J Med. 1971; 285(27):1493-1496.

6. Jones RB, Tervaert JW, Hauser T, et al. Rituximab versus cyclophosphamide in ANCA-associated renal vasculitis. N Engl J Med. 2010;363(3): 211-220.

7. Stone JH, Merkel PA, Spiera R, et al. Rituximab versus cyclophosphamide for ANCA-associated vasculitis. N Engl J Med. 2010;363(3):221-232.

8. Lee SS, Adu D, Thompson RA. Anti-myeloperoxidase antibodies in systemic vasculitis. Clin Exp Immunol. 1990;79(1):41-46.

9. van der Woude FJ, Rasmussen N, Lobatto S, et al. Autoantibodies against neutrophils and monocytes: tool for diagnosis and marker of disease activity in Wegener's granulomatosis. Lancet. 1985;1(8426): 425-429.

10. Lüdemann J, Utecht B, Gross WL. Anti-neutrophil cytoplasm antibodies in Wegener's granulomatosis recognize an elastinolytic enzyme. J Exp Med. 1990;171(1):357-362.

11. Jennette JC, Falk RJ. Pathogenesis of antineutrophil cytoplasmic autoantibody-mediated disease. Nat Rev Rheumatol. 2014;10(8): 463-473.

12. Falk RJ, Terrell RS, Charles LA, Jennette JC. Anti-neutrophil cytoplasmic autoantibodies induce neutrophils to degranulate and produce oxygen radicals in vitro. Proc Natl Acad Sci US A. 1990;87(11):4115-4119.

13. Huugen D, Xiao H, van Esch A, et al. Aggravation of anti-myeloperoxidase antibody-induced glomerulonephritis by bacterial lipopolysaccharide: role of tumor necrosis factor- $\alpha$. Am J Pathol. 2005;167(1):47-58.

14. Schreiber A, Xiao H, Jennette JC, Schneider W, Luft FC, Kettritz R. $\mathrm{C} 5$ a receptor mediates neutrophil activation and ANCA-induced glomerulonephritis. J Am Soc Nephrol. 2009;20(2):289-298.

15. Kessenbrock K, Krumbholz M, Schönermarck U, et al. Netting neutrophils in autoimmune small-vessel vasculitis. Nat Med. 2009;15(6): 623-625.

16. Ewert BH, Jennette JC, Falk RJ. Anti-myeloperoxidase antibodies stimulate neutrophils to damage human endothelial cells. Kidney Int. 1992; 41(2):375-383.

17. Savage CO, Gaskin G, Pusey CD, Pearson JD. Myeloperoxidase binds to vascular endothelial cells, is recognized by ANCA and can enhance complement dependent cytotoxicity. Adv Exp Med Biol. 1993;336: 121-123.

18. Xiao $\mathrm{H}$, Heeringa $\mathrm{P}, \mathrm{Hu} \mathrm{P}$, et al. Antineutrophil cytoplasmic autoantibodies specific for myeloperoxidase cause glomerulonephritis and vasculitis in mice. J Clin Invest. 2002;110(7):955-963.

19. Bansal PJ, Tobin MC. Neonatal microscopic polyangiitis secondary to transfer of maternal myeloperoxidase-antineutrophil cytoplasmic antibody resulting in neonatal pulmonary hemorrhage and renal involvement. Ann Allergy Asthma Immunol. 2004;93(4):398-401.

20. Martin F, Chan AC. Pathogenic roles of B cells in human autoimmunity: insights from the clinic. Immunity. 2004;20(5):517-527.

21. Voswinkel J, Müller A, Lamprecht P. Is PR3-ANCA formation initiated in Wegener's granulomatosis lesions? Granulomas as potential lymphoid tissue maintaining autoantibody production. Ann N Y Acad Sci. 2005;1051:12-19.

22. Voswinkel J, Mueller A, Kraemer JA, et al. B lymphocyte maturation in Wegener's granulomatosis: a comparative analysis of $\mathrm{VH}$ genes from endonasal lesions. Ann Rheum Dis. 2006;65(7):859-864.

23. Krumbholz M, Specks U, Wick M, Kalled SL, Jenne D, Meinl E. BAFF is elevated in serum of patients with Wegener's granulomatosis. J Autoimmun. 2005;25(4):298-302. 
24. Sanders JS, Huitma MG, Kallenberg CG, Stegeman CA. Plasma levels of soluble interleukin 2 receptor, soluble CD30, interleukin 10 and $\mathrm{B}$ cell activator of the tumour necrosis factor family during follow-up in vasculitis associated with proteinase 3-antineutrophil cytoplasmic antibodies: associations with disease activity and relapse. Ann Rheum Dis. 2006;65(11):1484-1489.

25. Nagai M, Hirayama K, Ebihara I, Shimohata H, Kobayashi M, Koyama A. Serum levels of BAFF and APRIL in myeloperoxidase anti-neutrophil cytoplasmic autoantibody-associated renal vasculitis: association with disease activity. Nephron Clin Pract. 2011;118(4): c339-c345.

26. Scapini P, Bazzoni F, Cassatella MA. Regulation of B-cell-activating factor (BAFF)/B lymphocyte stimulator (BLyS) expression in human neutrophils. Immunol Lett. 2008;116(1):1-6.

27. Tedder TF, Engel P. CD20: a regulator of cell-cycle progression of B lymphocytes. Immunol Today. 1994;15(9):450-454.

28. Weiner GJ. Rituximab: mechanism of action. Semin Hematol. 2010; 47(2):115-123.

29. Story CM, Mikulska JE, Simister NE. A major histocompatibility complex class I-like Fc receptor cloned from human placenta: possible role in transfer of immunoglobulin $\mathrm{G}$ from mother to fetus. J Exp Med. 1994;180(6):2377-2381.

30. Kuo TT, Aveson VG. Neonatal Fc receptor and IgG-based therapeutics. MAbs. 2011;3(5):422-430.

31. Ghetie V, Hubbard JG, Kim JK, Tsen MF, Lee Y, Ward ES. Abnormally short serum half-lives of IgG in $\beta 2$-microglobulin-deficient mice. Eur J Immunol. 1996;26(3):690-696.

32. Israel EJ, Wilsker DF, Hayes KC, Schoenfeld D, Simister NE. Increased clearance of $\operatorname{IgG}$ in mice that lack $\beta 2$-microglobulin:possible protective role of FcRn. Immunology. 1996;89(4):573-578.

33. Dostalek M, Gardner I, Gurbaxani BM, Rose RH, Chetty M. Pharmacokinetics, pharmacodynamics and physiologically-based pharmacokinetic modelling of monoclonal antibodies. Clin Pharmacokinet. 2013;52(2):83-124.

34. Golay J, Semenzato G, Rambaldi A, et al. Lessons for the clinic from rituximab pharmacokinetics and pharmacodynamics. MAbs. 2013;5(6): 826-837.

35. Regazzi MB, Iacona I, Avanzini MA, et al. Pharmacokinetic behavior of rituximab: a study of different schedules of administration for heterogeneous clinical settings. Ther Drug Monit. 2005;27(6):785-792.

36. Beers SA, French RR, Chan HT, et al. Antigenic modulation limits the efficacy of anti-CD20 antibodies: implications for antibody selection. Blood. 2010;115(25):5191-5201.

37. Vaughan AT, Iriyama C, Beers SA, et al. Inhibitory Fc $\gamma R I I b(C D 32 b)$ becomes activated by therapeutic $\mathrm{mAb}$ in both cis and trans and drives internalization according to antibody specificity. Blood. 2014; 123(5):669-677.

38. Reddy V, Cambridge G, Isenberg DA, Glennie MJ, Cragg MS, Leandro M. Internalization of rituximab and the efficiency of B cell depletion in rheumatoid arthritis and systemic lupus erythematosus. Arthritis Rheumatol. 2015;67(8):2046-2055.

39. Beum PV, Peek EM, Lindorfer MA, et al. Loss of CD20 and bound CD20 antibody from opsonized B cells occurs more rapidly because of trogocytosis mediated by Fc receptor-expressing effector cells than direct internalization by the B cells. J Immunol. 2011;187(6):3438-3447.

40. Muller C, Murawski N, Wiesen MH, et al. The role of sex and weight on rituximab clearance and serum elimination half-life in elderly patients with DLBCL. Blood. 2012;119(14):3276-3284.

41. Jäger U, Fridrik M, Zeitlinger M, et al. Rituximab serum concentrations during immuno-chemotherapy of follicular lymphoma correlate with patient gender, bone marrow infiltration and clinical response. Haematologica. 2012;97(9):1431-1438.

42. Carella AM, de Souza CA, Luminari S, et al. Prognostic role of gender in diffuse large B-cell lymphoma treated with rituximab containing regimens: a Fondazione Italiana Linfomi/Grupo de Estudos em Moléstias Onco-Hematológicas retrospective study. Leuk Lymphoma. 2013;54(1):53-57.
43. Weng WK, Levy R. Two immunoglobulin $\mathrm{G}$ fragment $\mathrm{C}$ receptor polymorphisms independently predict response to rituximab in patients with follicular lymphoma. J Clin Oncol. 2003;21(21):3940-3947.

44. Berinstein NL, Grillo-López AJ, White CA, et al. Association of serum rituximab (IDEC-C2B8) concentration and anti-tumor response in the treatment of recurrent low-grade or follicular non-Hodgkin's lymphoma. Ann Oncol. 1998;9(9):995-1001.

45. Li J, Zhi J, Wenger M, et al. Population pharmacokinetics of rituximab in patients with chronic lymphocytic leukemia. J Clin Pharmacol. 2012;52(12):1918-1926.

46. Ng CM, Bruno R, Combs D, Davies B. Population pharmacokinetics of rituximab (anti-CD20 monoclonal antibody) in rheumatoid arthritis patients during a phase II clinical trial. J Clin Pharmacol. 2005; 45(7):792-801.

47. Puisset F, White-Koning M, Kamar N, et al. Population pharmacokinetics of rituximab with or without plasmapheresis in kidney patients with antibody-mediated disease. Br J Clin Pharmacol. 2013;76(5):734-740.

48. Vieira CA, Agarwal A, Book BK, et al. Rituximab for reduction of anti-HLA antibodies in patients awaiting renal transplantation: 1. Safety, pharmacodynamics, and pharmacokinetics. Transplantation. 2004; 77(4):542-548.

49. Barcellini W, Zaja F, Zaninoni A, et al. Low-dose rituximab in adult patients with idiopathic autoimmune hemolytic anemia: clinical efficacy and biologic studies. Blood. 2012;119(16):3691-3697.

50. Blum S, Gillis D, Brown $\mathrm{H}$, et al. Use and monitoring of low dose rituximab in myasthenia gravis. J Neurol Neurosurg Psychiatry. 2011; 82(6):659-663.

51. Visentini M, Granata M, Veneziano ML, et al. Efficacy of low-dose rituximab for mixed cryoglobulinemia. Clin Immunol. 2007;125(1): 30-33.

52. Galarza-Maldonado C, Kourilovitch MR, Molineros JE, et al. The administration of low doses of rituximab followed by hydroxychloroquine, prednisone and low doses of mycophenolate mofetil is an effective therapy in Latin American patients with active systemic lupus erythematosus. Autoimmun Rev. 2010;10(2):108-111.

53. Horváth B, Huizinga J, Pas HH, Mulder AB, Jonkman MF. Low-dose rituximab is effective in pemphigus. $\mathrm{Br} J$ Dermatol. 2012;166(2): 405-412.

54. Moog P, Probst M, Kuechle C, Hauser C, Heemann U, Thuermel K. Single-dose rituximab for remission induction and maintenance therapy in ANCA-associated vasculitis: a retrospective analysis of 17 patients. Scand J Rheumatol. 2014;43(6):519-523.

55. Turner-Stokes T, Sandhu E, Pepper RJ, et al. Induction treatment of ANCA-associated vasculitis with a single dose of rituximab. Rheumatology (Oxford). 2014;53(8):1395-1403.

56. Specks U, Fervenza FC, McDonald TJ, Hogan MC. Response of Wegener's granulomatosis to anti-CD20 chimeric monoclonal antibody therapy. Arthritis Rheumatol. 2001;44(12):2836-2840.

57. Jones RB, Ferraro AJ, Chaudhry AN, et al. A multicenter survey of rituximab therapy for refractory antineutrophil cytoplasmic antibodyassociated vasculitis. Arthritis Rheumatol. 2009;60(7):2156-2168.

58. Seo P, Specks U, Keogh KA. Efficacy of rituximab in limited Wegener's granulomatosis with refractory granulomatous manifestations. J Rheumatol. 2008;35(10):2017-2023.

59. Cartin-Ceba R, Golbin JM, Keogh KA, et al. Rituximab for remission induction and maintenance in refractory granulomatosis with polyangiitis (Wegener's): ten-year experience at a single center. Arthritis Rheumatol. 2012;64(11):3770-3778.

60. Holle JU, Dubrau C, Herlyn K, et al. Rituximab for refractory granulomatosis with polyangiitis (Wegener's granulomatosis): comparison of efficacy in granulomatous versus vasculitic manifestations. Ann Rheum Dis. 2012;71(3):327-333.

61. Martinez Del Pero M, Chaudhry A, Jones RB, Sivasothy P, Jani P, Jayne D. B-cell depletion with rituximab for refractory head and neck Wegener's granulomatosis: a cohort study. Clin Otolaryngol. 2009; 34(4):328-335 
62. Pullerits R, Ljevak M, Vikgren J, Bokarewa M. Off-trial evaluation of the B cell-targeting treatment in the refractory cases of antineutrophil cytoplasmic antibodies (ANCA)-associated vasculitis: longterm follow-up from a single centre. Scand J Immunol. 2012;76(4): 411-420.

63. Charles P, Neel A, Tieulie N, et al. Rituximab for induction and maintenance treatment of ANCA-associated vasculitides: a multicentre retrospective study on 80 patients. Rheumatology. 2014;53(3): 532-539.

64. Mohammad AJ, Hot A, Arndt F, et al. Rituximab for the treatment of eosinophilic granulomatosis with polyangiitis (Churg-Strauss). Ann Rheum Dis. Epub 2014 Dec 2.

65. Muñoz SA, Gandino IJ, Orden AO, Allievi A. Rituximab in the treatment of eosinophilic granulomatosis with polyangiitis. Reumatol Clin. 2015;11(3):165-169.

66. Keogh KA, Ytterberg SR, Fervenza FC, Carlson KA, Schroeder DR, Specks U. Rituximab for refractory Wegener's granulomatosis: report of a prospective, open-label pilot trial. Am J Respir Crit Care Med. 2006; 173(2):180-187.

67. Keogh KA, Wylam ME, Stone JH, Specks U. Induction of remission by B lymphocyte depletion in eleven patients with refractory antineutrophil cytoplasmic antibody-associated vasculitis. Arthritis Rheumatol. 2005;52(1):262-268.

68. Kallenberg CG, Hauser T. B-cell therapy in antineutrophil cytoplasmic antibody-associated vasculitis. Nephrol Dial Transplant. 2015; 30 Suppl 1:i119-i122.

69. Specks U. Pro: Should all patients with anti-neutrophil cytoplasmic antibody-associated vasculitis be primarily treated with rituximab? Nephrol Dial Transplant. 2015;30(7):1083-1087.

70. Kronbichler A, Jayne DR. Con: Should all patients with anti-neutrophil cytoplasmic antibody-associated vasculitis be primarily treated with rituximab? Nephrol Dial Transplant. 2015;30(7):1075-1081.

71. Specks U, Ikle D, Stone JH. Induction regimens for ANCA-associated vasculitis. N Engl J Med. 2013;369(19):1865-1866

72. Lyons PA, Rayner TF, Trivedi S, et al. Genetically distinct subsets within ANCA-associated vasculitis. N Engl J Med. 2012;367(3):214-223.

73. Geetha D, Specks U, Stone JH, et al. Rituximab versus cyclophosphamide for ANCA-associated vasculitis with renal involvement. $J \mathrm{Am}$ Soc Nephrol. 2015;26(4):976-985.

74. Sanders JS, Huitma MG, Kallenberg CG, Stegeman CA. Prediction of relapses in PR3-ANCA-associated vasculitis by assessing responses of ANCA titres to treatment. Rheumatology (Oxford). 2006; 45(6):724-729.

75. Stegeman CA, Tervaert JW, Sluiter WJ, Manson WL, de Jong PE, Kallenberg CG. Association of chronic nasal carriage of Staphylococcus aureus and higher relapse rates in Wegener granulomatosis. Ann Intern Med. 1994;120(1):12-17.

76. Boomsma MM, Stegeman CA, van der Leij MJ, et al. Prediction of relapses in Wegener's granulomatosis by measurement of antineutrophil cytoplasmic antibody levels: a prospective study. Arthritis Rheumatol. 2000;43(9):2025-2033.

77. Tomasson G, Grayson PC, Mahr AD, Lavalley M, Merkel PA. Value of ANCA measurements during remission to predict a relapse of ANCA-associated vasculitis - a meta-analysis. Rheumatology (Oxford) 2012;51(1):100-109.

78. Henderson SR, Copley SJ, Pusey CD, Ind PW, Salama AD. Prolonged $\mathrm{B}$ cell depletion with rituximab is effective in treating refractory pulmonary granulomatous inflammation in granulomatosis with polyangiitis (GPA). Medicine (Baltimore). 2014;93(27):e229.

79. Shah S, Hruskova Z, Segelmark M, et al. Treatment of severe renal disease in ANCA positive and negative small vessel vasculitis with rituximab. Am J Nephrol. 2015;41(4-5):296-301.

80. Lovric S, Erdbruegger U, Kümpers P, et al. Rituximab as rescue therapy in anti-neutrophil cytoplasmic antibody-associated vasculitis: a single-centre experience with 15 patients. Nephrol Dial Transplant. 2009;24(1):179-185.
81. Khan A, Lawson CA, Quinn MA, Isdale AH, Green MJ. Successful treatment of ANCA-negative Wegener's granulomatosis with rituximab. Int J Rheumatol. 2010;2010:846063.

82. Smith KG, Jones RB, Burns SM, Jayne DR. Long-term comparison of rituximab treatment for refractory systemic lupus erythematosus and vasculitis: remission, relapse, and re-treatment. Arthritis Rheumatol. 2006;54(9):2970-2982.

83. Specks U. Biologic therapy in ANCA-associated vasculitis: new perspective. Ann Rheum Dis. 2015;74 Suppl 2:3.

84. de Groot K, Harper L, Jayne DR, et al. Pulse versus daily oral cyclophosphamide for induction of remission in antineutrophil cytoplasmic antibody-associated vasculitis: a randomized trial. Ann Intern Med. 2009;150(10):670-680.

85. Harper L, Morgan MD, Walsh M, et al. Pulse versus daily oral cyclophosphamide for induction of remission in ANCA-associated vasculitis: long-term follow-up. Ann Rheum Dis. 2012;71(6):955-960.

86. Walsh M, Flossmann O, Berden A, et al. Risk factors for relapse of antineutrophil cytoplasmic antibody-associated vasculitis. Arthritis Rheumatol. 2012;64(2):542-548.

87. Jones RB, Furuta S, Tervaert JW, et al. Rituximab versus cyclophosphamide in ANCA-associated renal vasculitis: 2-year results of a randomised trial. Ann Rheum Dis. 2015;74(6):1178-1182.

88. Jayne D, Rasmussen N, Andrassy K, et al. A randomized trial of maintenance therapy for vasculitis associated with antineutrophil cytoplasmic autoantibodies. $N$ Engl J Med. 2003;349(1):36-44.

89. Guillevin L, Pagnoux C, Karras A, et al. Rituximab versus azathioprine for maintenance in ANCA-associated vasculitis. $N$ Engl J Med. 2014;371(19):1771-1780.

90. Hellmich B, Flossmann O, Gross WL, et al. EULAR recommendations for conducting clinical studies and/or clinical trials in systemic vasculitis: focus on anti-neutrophil cytoplasm antibody-associated vasculitis. Ann Rheum Dis. 2007;66(5):605-617.

91. Smith RM, Jones RB, Guerry MJ, et al. Rituximab for remission maintenance in relapsing antineutrophil cytoplasmic antibody-associated vasculitis. Arthritis Rheumatol. 2012;64(11):3760-3769.

92. Pendergraft WF 3rd, Cortazar FB, Wenger J, et al. Long-term maintenance therapy using rituximab-induced continuous B-cell depletion in patients with ANCA vasculitis. Clin J Am Soc Nephrol. 2014;9(4): 736-744.

93. McGregor JG, Hogan SL, Hu Y, Jennette CE, Falk RJ, Nachman PH. Glucocorticoids and relapse and infection rates in anti-neutrophil cytoplasmic antibody disease. Clin J Am Soc Nephrol. 2012;7(2): 240-247.

94. Walsh M, Merkel PA, Mahr A, Jayne D. Effects of duration of glucocorticoid therapy on relapse rate in antineutrophil cytoplasmic antibodyassociated vasculitis: a meta-analysis. Arthritis Care Res. 2010;62(8): 1166-1173.

95. Azar L, Springer J, Langford CA, Hoffman GS. Rituximab with or without a conventional maintenance agent in the treatment of relapsing granulomatosis with polyangiitis (Wegener's): a retrospective singlecenter study. Arthritis Rheumatol. 2014;66(10):2862-2870.

96. Besada E, Koldingsnes W, Nossent JC. Serum immunoglobulin levels and risk factors for hypogammaglobulinaemia during long-term maintenance therapy with rituximab in patients with granulomatosis with polyangiitis. Rheumatology (Oxford). 2014;53(10):1818-1824.

97. Marco H, Smith RM, Jones RB, et al. The effect of rituximab therapy on immunoglobulin levels in patients with multisystem autoimmune disease. BMC Musculoskelet Disord. 2014;15:178.

98. Venhoff N, Effelsberg NM, Salzer U, et al. Impact of rituximab on immunoglobulin concentrations and B cell numbers after cyclophosphamide treatment in patients with ANCA-associated vasculitides. PloS One. 2012;7(5):e37626.

99. Roberts DM, Jones RB, Smith RM, et al. Immunoglobulin G replacement for the treatment of infective complications of rituximab-associated hypogammaglobulinemia in autoimmune disease: a case series. J Autoimmun. 2015;57:24-29. 


\section{Publish your work in this journal}

Therapeutics and Clinical Risk Management is an international, peerreviewed journal of clinical therapeutics and risk management, focusing on concise rapid reporting of clinical studies in all therapeutic areas, outcomes, safety, and programs for the effective, safe, and sustained use of medicines. This journal is indexed on PubMed Central, CAS,

EMBase, Scopus and the Elsevier Bibliographic databases. The manuscript management system is completely online and includes a very quick and fair peer-review system, which is all easy to use. Visit http://www.dovepress.com/testimonials.php to read real quotes from published authors.

Submit your manuscript here: http://www.dovepress.com/therapeutics-and-clinical-risk-management-journal 